\title{
Beliefs and attitudes of Welsh SMEs to marketing
}

Received (in revised form): 20th August, 2001

\section{Helen Murdoch BA MSc DipM MCIM}

is a marketing consultant specialising in small and medium enterprises (SMEs). She is based in the South Wales Valleys, and has close associations with the Welsh TECs and the Welsh Development Agency.

\section{Haydn Blackey BA MA DipM MCIM}

is Associate Director of the Glamorgan Business School, and Principle Lecturer in Marketing at the University of Glamorgan. His research interests include strategic marketing within SMEs, and the marketing of religion.

\section{Jim Blythe BA MPhil MAEdD DipM MCIM}

is Reader in Marketing at Glamorgan Business School. A former company director and business consultant, his research interests include exhibitions and trade fairs, and the relationship between marketing and sales. He is the author of several textbooks, and numerous papers.

\begin{abstract}
The Welsh economy has recently gone through a period of transition in which nationalised industries such as coal and steel have been replaced by small businesses, often sponsored by government agencies. This research reports on the degree to which these new small and medium-size enterprises (SMEs) are able to apply marketing thinking to the business.

The research found that SMEs in Wales show good customer orientation, but patchy understanding of competitive positioning and virtually no knowledge of strategic marketing thinking. Marketing was seen as a functional activity, often carried out by junior staff. Recommendations are made both for marketing education in Wales and similar regions, and for further research.
\end{abstract}

\section{INTRODUCTION}

At the start of 1999 there were 75,000 VAT-registered businesses in Wales. The number of small business start-ups in the first half of 1997 was 13,000, representing 4.8 per cent of the total and an increase of almost 40 per cent over the 1996 figure. The growth of small and medium-sized enterprises (SMEs) in Wales has been fuelled by various government initiatives

Haydn Blackey Glamorgan Business School, Treforest, Mid-Glamorgan CF37 1DL, Wales.

Tel: 01443 480480; Fax: 01443 482380; e-mail: hblackey@glam.ac.uk (the Valleys Initiative, the Welsh

Development Agency and European

Regional Development initiatives) as a response to the disappearance of the nationalised heavy industries (coal mining and steel) which characterised employment in South Wales until the early 1980s. Because of the previous domination of these sunset industries, there has not been a tradition of entrepreneurship in the country, and there is a lack of an enterprise culture.

Successive governments have seen SME growth as a way of reducing unemployment, and have (in their different ways) been prepared to invest in creating an enterprise culture: these initiatives have met with mixed success, and have occasionally been considered to be cosmetic exercises, but there is little doubt that SMEs have created many new jobs in Wales. 
The importance of SMEs to the economy has been reflected in the wealth and diversity of research which has appeared over the past two decades. Since the 1980s and particularly in the 1990s there has been an explosion of research into entrepreneurship and the small and medium-sized enterprise. ${ }^{1-12}$ The link between entrepreneurism and small businesses has been examined and reported on, and the similarities between the characteristics of successful small businesses and entrepreneurs put under the microscope. Competence in marketing is often cited as a key determinant in the success of the small firm, many authors ${ }^{13-20}$ go so far as to say that lack of marketing skill is a key cause of company failure, which goes rather further than statements to the effect that lack of marketing limits success. There are many practical publications of the 'How to do marketing in small businesses' variety and many nuts and bolts manuals on running elements of a marketing campaign.

Carson $^{21}$ sees the characteristics of successful small business owners as 'being highly motivated, ambitious, domineering and inspirational'. In his view, small business owners tend to be generalists rather than specialists, they take risks, and are task oriented. In most cases the owner-manager is personally involved in all aspects of the firm's operations and his or her culture and background play a distinct and important part. Carson also states that inadequate marketing is a commonly identified reason for small business failure and is recognised as a weakness for small businesses generally. The scope of marketing is often misunderstood by small businesses which regard marketing from an operational sales-orientated perspective ('I don't need a marketing man, I want men who can sell!').

Smallbone ${ }^{22}$ concluded that marketing was the key problem influencing performance of firms at business start-up stage. An earlier survey ${ }^{23}$ of newly established firms also determined that the ability of the owner-manager to judge appropriate market opportunities was a key discriminator of probable success. In the case of small businesses that have been established for some years, Slatter and Lovett ${ }^{24}$ proposed that a lack of marketing was a key cause of company failure. Gill ${ }^{25}$ in a longitudinal study of the problems facing small firms reported that locating and retaining customers has a major impact on performance.

Marketing is seen by many researchers to be relevant to small businesses only at the start-up stages. ${ }^{26-28}$ After that it moves to being less important and is perceived as a minor issue. Market positioning, niche marketing, market segmentation and market and competitor analysis and research are treated as minor or secondary strategic tactics. ${ }^{29}$

Alternatively, marketing is only perceived as important when small firms experience change, ie need to grow and expand or are in a crisis of survival. ${ }^{30-32}$ At that stage such companies turn to marketing for a 'quick fix'.

The transferability of the marketing concept almost universally continues to be a major topic of academic discussion. ${ }^{33-35}$ Small businesses, however, are different - they operate under severe resource constraints, they typically lack specialised marketing expertise and often have quite different marketing objectives, often seeking to ensure controlled growth rather than the sales maximisation, market share and profit goals of larger organisations. ${ }^{36}$ These factors are themselves sufficient to question the assumption that marketing in large businesses is transferable to the small business situation.

It would appear, then, that rather than questioning whether successful 
entrepreneurs or small businesses adopt marketing principles, the question should be how they structure this element of their business. Some authors ${ }^{37-39}$ are now proposing that an entrepreneurial, rather than classic, marketing style is more appropriate for the smaller firm.

Murray ${ }^{40}$ contends that marketing is the role which could most ably adapt to become the 'entrepreneurial homeland'. Marketing is, he claims, more innovative, more socially aware and more entrepreneurial than other decision-making areas of the company. His assessment of the characteristics of marketing managers in large businesses echoes the characteristics identified here as unique to small business owners and entrepreneurs, leading to the assumption that marketing and entrepreneurism sit comfortably together, and that it is a tension between classic marketing structure and entrepreneurial marketing style that provokes so much of the discussion.

A formal strategic marketing plan, with its principal focus being the identification and creation of a competitive advantage, is seen to be a source of significant benefits to any organisation. ${ }^{41}$ Bonoma $^{42}$ says that marketing has for a number of years been long on advice about what to do in a given competitive or marketing situation, and short on useful recommendations on how to do it within company, competitor and customer constraints.

The literature shows that a number of attempts have been made to produce complex theories and formal procedural models for marketing planning in small businesses, ${ }^{43-46}$ however the approaches vary considerably and are amended and adapted in subsequent studies. None of the theories or models has been adopted by practitioners and no coherent direction or guidance has been given.
Lancaster and Waddelow ${ }^{47}$ found evidence that the complexity of strategic marketing planning was off-putting for SMEs, leading to a prejudice against it. On the other hand, Walker et al. ${ }^{48}$ showed that firms with formal plans outperform those without formal plans.

\section{THE RESEARCH}

To echo the spread of business in the south Wales area, it was decided that the following industry sectors should be included in the sample: retail, tourism and leisure, service and manufacturing. The purpose of this was to obtain as balanced a viewpoint as possible and to identify any significant differences in each of the industry sectors. The firms were all small, serving their local area or a very small niche market. Consideration was also given to the job function and job level of the potential interviewee. The reasons for doing this was to ensure that those interviewed were in positions of authority and were recognised as having sufficient overall knowledge of their organisation at a decision-making level.

In all 17 interviews were conducted: all respondents were either owner-managers or senior directors and all had some marketing, sales or customer responsibility. Having decided to adopt a loosely structured approach to the interviews, a list of the issues to be investigated was constructed. An integral element in the interview design was to give full weight to the information gleaned from the literature review. This was vital in determining what kind of questions need to be asked. The areas considered appropriate for investigation were based on the Hogarth-Scott et al. ${ }^{49}$ research which sought to investigate the small business owners' understanding of marketing concepts and attitudes to marketing. The areas identified for investigation were: 
- customers and customer focus

- competitive advantage and positioning

- marketing communications and techniques

- marketing planning and structure

- specific marketing issues, challenges and opportunities.

A list of questions used by Carson and Cromie $^{50}$ was used to structure the interviews. These questions are repeated here:

1. Could you tell me something about the market(s) for your product(s)/ service(s)?

2. Tell me something about your competitors.

3. Why do your customers buy from you rather than from your competitors? What advantage do you offer them that the competition cannot meet?

4. Could you tell me something about your customers? How many do you have? Who are your key customers?

5 . Where do you gather information that lets you know what is happening in your markets? How do you keep in touch with changes in your market?

6. What do you consider to be the most important event in your market over the past few years?

7. What methods do you use to promote your products or services?

8. Tell me about your communication with customers after you have supplied them with goods and services.

9. Could you tell me how you go about setting the price for your goods and services? What are the principles underlying your pricing?

In order to investigate the importance of marketing to small businesses, it was decided to open the interviews by asking a general question to determine the business area which was felt to be the most important to each respondent. At the end of the interviews, respondents were asked specific questions about their attitudes towards marketing and also what level of marketing planning they undertook.

The sequencing of the questions was significant, starting wide with as broad a scope as possible and narrowing to specific points at the end of the interview.

\section{RESEARCH FINDINGS}

\section{Customers and customer focus}

Most of the respondents had a good customer orientation and were keen to satisfy their customers' wants and needs. There was a broad recognition that companies needed to understand what people want and many companies attempted to tailor the product or service to those needs. The idea that the 'customer is king' was repeated by a number of respondents and several stated that without customers they would have no business. Within the service sector, several respondents emphasised the need to treat every customer as unique and there was clear evidence of a strong customer orientation. The retail and tourism and leisure sectors concentrated on treating each customer as special, often evident in the personal service that was provided. Respondents in the manufacturing sector dealt with much smaller numbers of customers, due to the specialised nature of the products. They had detailed knowledge of their customers' needs and wants, and of necessity tailored their products accordingly. They, however, exhibited a strongly product-oriented approach to business and there was a tendency merely to pay lip service to marketing.

Many of the interviewees had in-depth knowledge of their customer base and employed segmentation and targeting in a sophisticated way. A wide 
range of information on customers was held in systems ranging from

sophisticated computer databases to shoe boxes full of paper. Customers were segmented into specific groups defined by a variety of criteria. In the consumer markets location, lifestyle, shopping behaviour and purchasing power were cited by different respondents as important factors. In the business-to-business markets, size and nature of business, location and managerial structure were mentioned. Having segmented their markets, most companies used this to assist them with their targeting or at least to provide a focus for their efforts. A number of respondents, however, felt that although they were aware of various customer segments, they cast their net wide and targeted 'everyone'. Some were not sure how to target each segment they had identified and questioned whether it was economically viable to do so. In the retail sector there was a general awareness that companies needed to balance the range of goods in order to appeal to different customer types and, therefore, maximise sales potential. Some retailers, however, tried to be 'all things to all people' and in so doing failed to achieve success with any of the identified groups.

Several businesses placed emphasis on the value of repeat business and a small number of businesses defined customers in a wider sense than 'just those who buy' to include those who use or influence the purchase. In these cases sophisticated targeting was used to ensure these vital segments were addressed.

The need to keep up-to-date with what customers want was acknowledged and several respondents gave examples of talking and listening to customers and then acting on that information. These were generally informal gatherings rather than formal research sessions. None of the respondents undertook ongoing market research in a formal way, although a number cited examples of the research undertaken when the company was started.

\section{Competitive advantage and positioning}

Responses in this area varied considerably. Some respondents were knowledgeable about their competition due to considerable experience in the sector. Others did not consider they had any competition, believing their business to be unique. A number of companies had a narrow view of their competitive arena, focusing primarily on product competition rather than industry, form or generic competition. Particular examples of this were observed in the tourism and leisure sector, where a number of respondents identified their competition only in terms of those offering a similar price and benefits package, ignoring competition from other price levels or indeed other forms of entertainment and leisure.

The lack of competitive information meant that a number of respondents described their competitive advantage in terms of the benefits their product gives to customers without relating this to the competition. Several businesses tried to establish their competitive advantage by offering additional or improved benefits compared to their competitors. In the tourism and leisure sector this was ease of booking, a wider choice of menus and additional facilities. One respondent in the retail sector offered a highly personalised service. For most respondents in the service sector competitive advantage revolved around standards of service and quality issues. This was expressed by one company as a commitment to 'keep our promises'.

In competitive markets, positioning was a conscious process. The most 
sophisticated response was from a company in the service sector whose positioning focused on superior quality, personal service, flexibility and extensive experience. This differentiated them from immediate and distant competitors and provided a clear focus for all their marketing activity. Another company whose business straddled both the service and manufacturing sector, were aware that their market was competitive and price sensitive. To compete in this arena would involve them in a price war. Their strategy therefore was to concentrate less on price and to identify specific niche markets where they could tailor their offer precisely to that target audience.

Respondents whose competitive awareness was more limited tended to focus on price as a key to their positioning. In the retail sector this was linked to the variety and range of stock available and in the tourism and leisure sector, the range of facilities on offer. Those who seemed to enjoy greater success in these areas tended to create a package of benefits, rather than focusing on a single issue. The competitive advantage was described in terms of the benefit accrued by the customer but did not detail how their offer differed from their competition. The benefits of a clear positioning was generally not understood by respondents in this grouping.

None of the respondents undertook formal information gathering, but many used a range of informal techniques. This included keeping up-to-date with general and specific media coverage, reading trade and consumer magazines, networking both formally and informally and through membership of trade associations and business clubs.

\section{Marketing communications techniques}

Respondents tended to define 'marketing' in terms of techniques for communicating with their customers and promoting their products. This focused especially on advertising but included other forms of promotion such as leaflets, mail shots, press releases and so on.

There was a strong tendency to regard advertising as being ineffective and a 'waste of money' and to consider word-of-mouth communications as the most appropriate and by far the best method of promoting business and gaining new customers. This was especially true in the service sector. A few respondents thought that advertising in the local press was successful. The tourism and leisure sector found this technique useful, especially when advertising was combined with a specific offer or promotion.

Public relations (PR) was the least understood of all the marketing communications techniques employed. The main reason appeared to be an inability to present newsworthy stories; press releases merely contained flat information, resulting in little media coverage, discouraging companies from trying the technique again. This led to a view that $P R$ does not work and is not worth the effort involved.

Most respondents used some marketing communications activities, selecting appropriate activity from mail shots, support literature, exhibitions and events, telemarketing, public relations, networking, websites and personal selling. A minority employed a mix of techniques to create a fully integrated marketing and communications package. Those employing fairly sophisticated techniques had also created distinctive corporate identities and made good use of image marketing to communicate their messages.

Respondents lacked detailed knowledge about marketing communications techniques and the skill to know how best to implement 
different activities. They often had unrealistic expectations in terms of the cost of the activity and the expected results. Respondents were often limited in their scope of activity, due mainly to lack of experience, knowledge and skills. This was particularly true of direct mail, which was highlighted as a disaster area by a number of respondents. If a particular technique proved effective and produced positive results, there was a tendency to repeat the technique continually, resulting in diminishing returns over time and a loss of confidence in the effectiveness of marketing. Although respondents acknowledged their lack of expertise, few sought external advice or assistance, believing it to be expensive and outside their reach.

Some marketing communication techniques were seen to be 'essential' for any business. This included producing brochures and leaflets and creating an identity. For the majority of respondents who held this view, little thought was given to the purpose of these materials and they acted merely as 'decoration'. Most businesses had a corporate identity, although often this was little more than a name and logo. Few respondents attempted to use their identity in an integrated way to communicate a corporate image and the identity was not used in a consistent manner across a range of activities.

The tourism and leisure sector gave examples of cooperative activity that they had undertaken, usually in conjunction with the Wales Tourist Board. This was seen to give the company greater power and visibility, making them appear a 'bigger player'. Two companies in the service sector also participated in cooperative activity, linking in with the local Training \& Enterprise Council (TEC). The prime motivation for this activity appeared to be closer contact with the TEC rather than to promote the business to a wider audience.

In a few instances respondents felt that they did not need to promote their business due to the success and volume of business they already had and, in a second example, due to limitations on their capacity to respond and take on further work. One respondent in the manufacturing sector, who was reluctant to undertake promotional activity, recognised that it was necessary in order to reduce the dependency on their existing customer base and to assist them to develop new markets. This company had relied strongly on one major customer, who had recently considerably reduced their orders; they were eager to replace this lost business and to spread the risk, so employed a range of direct contact promotional activity.

\section{Marketing planning and structure}

Only one of the respondents undertook any formal marketing planning with a specifically allocated marketing budget. A number of companies undertook no planning at all and operated on a purely reactive basis. The majority of respondents did at least think about the future and discussed where the business was going. The process was informal and generally not documented.

The majority of respondents had, however, prepared a business plan. This process appeared to be driven by the TECs, and to some extent the banks, as a prerequisite for obtaining advice and funding. In some cases the achievement of quality awards and standards, such as Investors in People and ISO9000, involved the company in producing formal business plans. Marketing was a small subsection of the general business plan, receiving limited attention in most cases. Respondents stated that their business plans were longer-term plans, 
covering on average a 12 to 18 -month period, and that they perceived marketing to be a short-term activity. This reinforces the view that marketing is an activity rather than a strategic function.

No formal marketing models or theories were referred to during the interviews and it was clear that none of the respondents employed these concepts either in a structured or informal way. In terms of understanding buyer behaviour, the tendency was to regard the process as a need-awareness-action model. A small number of respondents refined this to include an influencer's role, but there was no evidence of a sophisticated understanding of this area.

Responses to the issue of specific marketing budgets were along similar lines. Finance was made available 'as required' and 'in response to a specific need', rather than in a planned and coordinated manner. There appeared to be a general reluctance to spend money on marketing as it was seen to be 'expensive' and ineffective. In a few cases, although no budget was allocated, there appeared to be an informal agreement that a certain sum would be spent on marketing activity. Comment was made regarding the drive from the TECs and Enterprise Agencies to recognise the value of marketing and to formalise marketing plans. Finance and assistance was generally available, although this primarily focused on strategic thinking and planning documentation. Respondents accepted the value of this, but were looking for more practical help and advice, which would enable them to achieve short-term sales objectives. A number of examples of the sort of information which they felt would be helpful were given. This included advice on which activity was the most appropriate for particular circumstances and what results could be expected; how they might initiate certain types of activity, eg access databases, select and manage specialist agencies, etc. and what level of activity, in terms of both time and expenditure, was required to achieve their objectives.

Only two of the companies had specific staff allocated to marketing roles, and in both instances the role incorporated sales and/or customer care in the title. Marketing was generally the responsibility of the owner manager or a senior director, although the implementation of activity was often handed down to a junior member of staff. There was little or no marketing experience or formal marketing training within the companies. An exception to this was one company in which the owner-manager had extensive marketing experience and was a member of the Chartered Institute of Marketing. This company, in the service sector, had a much more sophisticated understanding of marketing, employed more sophisticated techniques and appeared to enjoy greater success. Several companies provided services to the marketing industry and claimed extensive, in-depth marketing knowledge. In reality their marketing understanding was naive and limited to technical knowledge of the area in which they operated, eg design, print and Internet services. Several companies attended training courses run by the TEC, Enterprise Agencies or Chamber of Commerce, usually covering specific marketing techniques and run over a single day. Many referred to manuals and 'How to' handbooks for information or asked colleagues and peers how they had undertaken certain activity. Most of these sources of information still left gaps in their knowledge, particularly in terms of actual costs and expected results, eg the number of enquiries expected from a mail shot; cost of black and white advertising in the local press 
etc. Learning was generally a 'hands-on' concept, and there appeared to be a great deal of trial and error. None of the respondents had undertaken any kind of testing of activity. Once an activity was decided on, the full programme was set in motion to run its full course.

\section{Attitudes to marketing}

Most respondents stated that marketing was very important and that they should be concentrating more effort in that area and doing more activity. Once more the emphasis was on 'doing' rather than 'thinking'. Generally companies were aware of changes in their markets and how those changes impacted on their business. They also recognised the need to develop, change and adapt constantly if they are to achieve growth and succeed in the future. The biggest challenge for most respondents was how to manage this greater emphasis on marketing and how to integrate it into their day-to-day business activity. The issues of time, cost and lack of skills and personnel were all cited as reasons for not 'doing more marketing'. The researcher also identified a concern from a number of respondents that if they focused more on marketing, they might make costly mistakes which could be very visible. This was demonstrated by a lack of confidence and hesitancy about marketing.

There was very little understanding of marketing as a strategic planning tool, and the marketing concept was employed by default rather than through planned effort. For most respondents marketing represented an action plan or series of activities, often as a support to selling. It was not coordinated, planned or consistent and often was the product of reacting to situations. This resulted in a simplistic and piecemeal approach. Examination of external and internal influences occurred in only a few instances and then in a very elementary way. Two companies adopted a more sophisticated approach, although this was informal and not documented. Neither of these businesses took full advantage of their approach, due primarily to the day-to-day operational pressures of running a small business.

The majority of respondents viewed customers as the most important aspect of their business, and most were aware of the competitive arena in which they operated. For many the link to marketing was not understood, and they questioned the breadth and scope of the research questions. Other areas which were often not perceived as having anything to do with marketing were pricing - a finance function - and significant market events - information, but of little relevance to the business unless in an operational sense. These respondents were primarily of the 'marketing as an activity' school of thought.

There was little difference within the four industry sectors in the attitude to or implementation of marketing.

Manufacturing was perhaps the least marketing-oriented and least sophisticated in the approach and techniques used. The retail and tourism and leisure sectors were highly competitive markets and exhibited similar attitudes towards marketing. Their approaches were quite simplistic and naive, and focused on a series of separate activities. Most respondents in these areas did attempt to define a competitive advantage, and did discuss where they wanted to be in the future. On the other hand, they did not fully develop their marketing to achieve their objectives. Respondents in the service sector demonstrated the most sophisticated approach to marketing. This seemed to originate from a need to define their service in terms the customer 
could understand and relate to. This was also the area in which several

respondents had some previous

experience or knowledge of marketing.

\section{CONCLUSION}

The research study provided a great deal of information in all areas of enquiry. In summary, all the small businesses which took part in the study undertake some marketing, although the degree of complexity and sophistication varied considerably. There was little difference in attitude or understanding across the four industry sectors and all employed similar marketing techniques.

Many consider just the most basic approach to marketing. For them, marketing is seen as a standalone activity, the product of reacting to situations, and immediate visible results are demanded of each individual activity.

At the other end of the scale, a number of companies adopted more sophisticated approaches, reviewing the external environment and internal position to determine future direction. This process was not, however, formalised and lacked cohesion and consistency.

The majority of respondents fell between these two positions. They generally had a well-developed understanding of their customers and competitive environment, could identify a competitive advantage and used several proactive marketing techniques and promotional methods. Again there was a wide variance in the coordination of their marketing effort and little integration into the business as a whole.

Almost all the businesses had a formal business plan, often driven by the TEC or local Enterprise Agency. The business plan was generally seen as a requirement to access TEC support, rather than as a 'blueprint' for managing and developing the business. Marketing was a necessary part of this plan but again not deemed to be of value in terms of achieving results.

The main barriers to marketing were cost and lack of time due to day-to-day pressures of running a small business. In addition, the majority of respondents lacked the knowledge, skills and expertise to undertake more sophisticated marketing. In most firms marketing was part of a wider job description and often the implementation was handled by junior, inexperienced staff. There was also a general lack of awareness of where to go to get advice and assistance that was practical and appropriate to their particular business.

The view of small businesses as risk-takers ${ }^{51}$ is not demonstrated in their attitude or approach to marketing. Most small businesses appear to exhibit a reluctance to undertake any marketing activity unless the outcome is clearly identified and their approach to marketing could be more accurately described as risk averse. The emphasis on small businesses being innovative and creative is also not apparent in the area of marketing. The lack of confidence about their abilities in marketing and lack of knowledge of the marketing arena would seem to account for this mismatch of findings.

A positive factor identified is the intimate knowledge SME owners have of their customers. ${ }^{52}$ This was clearly evident in most of the interviews: even when the customer base was large, the small business owner was aware of its composition and requirements.

It is the view of many researchers that marketing is only relevant to small business at the start-up stage or as a 'quick fix' in crisis circumstances. ${ }^{53-58}$ This is not supported by the research reported here. Most businesses described ongoing changes in their markets and acknowledged the need to adapt and 
develop their products and services. Marketing is therefore relevant no matter what the firm's stage of development.

The driving force for business planning was clearly identified as the Training \& Enterprise Councils (TECs). All the TECs covering Wales encourage and assist small businesses to produce business plans which in turn enables those businesses to access a variety of TEC, government and European support. The business plan is seen as being instrumental in obtaining support, but is not necessarily put into action thereafter. In other words, the business plan goes straight back on the shelf after the meeting with the bank manager. Presumably, if the TECs provided a stronger focus on marketing within the general business planning process, small businesses would begin to develop a better understanding of marketing and its role in making strategic decisions, but might still not implement the findings.

The issue of whether classic marketing concepts and theories can be transferred from the domain of large organisations to small businesses is a key theme identified by academics. The academic research suggests that marketing principles are as applicable to small business as they are to large business: the basic concepts of customer orientation and focus, market segmentation, targeting, positioning and competitive advantage apply as much to small business as they do to large organisations. The question seems to be less to do with the transferability of marketing principles, and more to do with the way those principles are applied. In large businesses the complexity of the organisational structure may warrant formal procedures and systems for decision making. This is not the case in small business. Small businesses are more personally run and staff have closer working relationships with their colleagues. There is constant interaction between staff and with customers and the market.

Overall, it seems evident that small firms have at best a simplistic view of marketing, and at worst a fear of it. Planning is only undertaken at the behest of banks and TECs, and such marketing orientation as is achieved is only achieved by default - the owners of the firms have to be close to the customers because they do not have enough staff to hide from them. Despite this, most small firms do at least pay lip service to the idea that marketing is a good thing: whether they actually understand what marketing is, is another matter entirely.

\section{References}

1 Davis, C. D., Hills, G. E. and LaForge, R. W. (1980) 'The marketing/small enterprise paradox: A research agenda', International Small Business Journal, Vol. 3, No. 3, pp. 31-42.

2 Murray, J. A. (1981) 'Marketing is home for the entrepreneurial process', Industrial Marketing Management, No. 10, pp. 93-99.

3 Kirby, D.A. (1990) 'Management education and small business development: An exploratory study of small firms in the UK', Journal of Small Business Management, Vol. 28, No. 4, pp. 78-87, October.

4 North, D., Leigh, R. and Smallbone, D. (1992) 'A comparison of surviving and non-surviving small and medium-sized manufacturing firms in London during the 1980s', Caley, K., Chell, E., Chittenden, F. and Mason, C. (eds) 'Small enterprise development policy and practice in action', Paul Chapman, London.

5 Keeble, D., Bryson, J. and Wood, P. (1992) 'Entrepreneurship and flexibility in business services: The rise of small management consultancy and market research firms in the UK', in Caley, K., Chell, E., Chittenden, F. and Mason, C. (eds) 'Small enterprise development policy and practice in action', Paul Chapman, London.

6 Osborne, R. L. (1993) 'Why entrepreneurs fail and how to avoid the traps', Management Decision, Vol. 31, No. 1, pp. 18-21.

7 Osborne, R. L. (1995) 'The essence of entrepreneurial success', Management Decision, Vol. 33, No. 7, pp. 4-9.

8 Fuller, P. B. (1994) 'Assessing marketing in small and medium sized enterprises', European Journal of Marketing, Vol. 28, No. 12, pp. 34-49.

9 Gadenne, D. (1994) 'Critical success factors for small business: An inter-industry comparison', International Small Business Journal, Vol. 17, No. 1, pp. 36-56.

10 Romano, C. and Ratnatunga, J. (1995) 'The role of marketing: Its impact on small enterprise research', 
European Journal of Marketing, Vol. 29, No. 7, pp. 9-30.

11 Siu, W. and Kirby, D. A. (1998) 'Approaches to small firm marketing: A critique', European Journal of Marketing, Vol. 32, No. 1/2, pp. 40-60.

12 McLarty, R. (1998) 'Case study: Evidence of a strategic marketing paradigm in a growing SME', Journal of Marketing Practice: Applied Marketing Science, Vol. 4, No. 4, pp. 105-117.

13 Watkin, D. G. (1986) 'Towards a competitive advantage: A focus strategy for small retailers', Journal of Small Business Management, Vol. 24, No. 1, pp 9-15, January.

14 Neil, T. (1986) 'Distinctive competence: A marketing strategy for survival', Journal of Small Business Management, Vol. 24, No. 1, pp. 16-21, January.

15 O'Neill, H. M. and Duker, J. (1986) 'Survival and failure in small business', Journal of Small Business Management, Vol. 24, No. 1, pp. 30-37, January.

16 Moeller, K. and Antilla, M. (1987) 'Marketing capability - A key success factor in small business', Journal of Marketing Management, Vol. 3, No. 2, pp. 185-203.

17 Fuller P. B. (1994) 'Assessing marketing in small and medium-sized enterprises', European Journal of Marketing, Vol. 28, No. 12, pp. 34-49.

18 Hogarth-Scott, S., Watson, K. and Wilson, L. (1996) 'Do small business have to practise marketing to survive and grow', Marketing Intelligence and Planning, Vol. 14, No. 1, pp. 16-18.

19 Gadenne (1994) op. cit.

20 McLarty (1998) op. cit.

21 Carson, D. (1991) 'European Journal of Marketing', Marketing Intelligence and Planning, Vol. 9, No. 6, pp. 7-9.

22 Smallbone, D., North, D. and Leigh, R. (1993) 'Support for mature SMEs: Developing a policy agenda', in Chittenden, F., Robertson, M. and Watkins, D. (eds) 'Small firms recession and recovery', Paul Chapman, London.

23 Milne, T. and Thompson, M. (1986) 'Patterns of successful business start-up', in Faulkner, R. (ed.) 'Readings in small business', Gower, Aldershot.

24 Slatter, S. and Lovett, D. (1999) 'Corporate turnaround', Penguin, Harmondsworth.

25 Gill, J. (1985) 'Factors affecting the survival and growth of the smaller company', Gower, Aldershot.

26 Alpander, G. G., Carter, K. D. and Forgren, R. A. (1990) 'Managerial issues and problem-solving in the formative years', Journal of Small Business Management, Vol. 28, No. 2, pp. 9-19, April.

27 Jennings, P. and Beaver, G. (1992) 'The performance and competitive advantage of small firms: A management perspective', International Small Business Journal, Vol. 15, No. 2, pp. 63-75.

28 Hannon, P. D. and Atherton, A. (1998) 'Small firm success and the art of orienteering: The value of plans, planning and strategic awareness in the competitive small firm', Journal of Small Business and Enterprise Development, Vol. 5, No. 2, pp. 102-119, Summer.
29 Siu and Kirby (1998) op. cit.

30 Chisnall, P. M. (1987) 'Small firms in action: Case studies in entrepreneurship', McGraw-Hill, London.

31 Smallbone, D. (1990) 'Success and failure in new business start-ups', International Small Business Journal, Vol. 13, No. 3, pp. 34-47.

32 Barkham, R., Gudgin, G., Hart, M. and Harvey, E., (1996) 'The determinants of small firm growth: An inter-regional study in the UK 1986-1990', The Regional Studies Association, Jessica Kingsley, London.

33 Houston, F. S. (1986) 'The marketing concept: what it is and what it is not', Journal of Marketing, Vol. 50, pp. 81-87, April.

34 Baker, M. J. (1987) 'One more time: What is marketing?', 'The marketing book', Heinemann, London.

35 Narver, J. C. and Slater, S. F. (1990) 'The effect of a market orientation on a business profitability', Journal of Marketing, pp. 20-35, October.

36 Gilmore, A., Carson, D. and Grant, K. (2001) 'SME marketing in practice' Marketing Intelligence and Planning, Vol. 19, No. 1.

37 McLarty (1998) op. cit.

38 Carson (1991) op. cit.

39 Chaston, I. (1997) 'Small firm performance: assessing the interaction between entrepreneurial style and organisational structure', European Journal of Marketing, Vol. 31, No. 11/12, pp. 814-831.

40 Murray (1981) op. cit.

41 McDonald, M. (1989) 'Ten barriers to marketing planning', Journal of Marketing Management, Vol. 5, No. 1, pp. 1-18.

42 Bonoma, T. (1985) 'The marketing edge: Making strategies work' quoted in Piercy, $\mathrm{N}$ and Peattie, K. J. 'Matching marketing strategies to corporate culture: The parcel and the wall', Journal of General Management, Vol. 13, No. 433.

43 Blois, K. J. (1989) 'Marketing in five "simple" questions!', Journal of Marketing Management, Vol. 5, No. 2, pp. 113-121.

44 Carson, D. (1990) 'Some exploratory models for assessing small firms' marketing performance (a qualitative approach)', European Journal of Marketing, Vol. 24, No. 11.

45 Brooksbank, R. (1996) 'The BASIC marketing planning process: A practical framework for the smaller business', Marketing Intelligence and Planning, Vol. 14, No. 4, pp. 16-23.

46 Lancaster, G. and Waddelow, I. (1998) 'An empirical investigation into the process of strategic marketing planning in SMEs: Its attendant problems and proposals towards a new practical paradigm', Journal of Marketing Management, Vol. 14, pp. 853-878.

47 Ibid.

48 Walker, O. C., Boyd, H. and Lareche, J. C. (1992) 'Marketing strategy: Planning and implementation', Irwin, Toronto.

49 Hogarth-Scott et al. (1996) op. cit.

50 Carson, D. and Cromie, S. (1989) 'Marketing planning in small enterprises: A model and some empirical evidence', Journal of Marketing Management, Vol. 5, No. 1, pp. 33-49. 
51 Carson (1991) op. cit.

52 Chisnall (1987) op. cit.

53 Alpander et al. (1990) op. cit.

54 Jennings and Beaver (1992) op. cit.
55 Hannon and Atherton (1998) op. cit.

56 Chisnall (1987) op. cit.

57 Smallbone (1998) op. cit.

58 Barkham et al. (1996) op. cit. 
